\title{
Neuromodulation of Whisking Related Neural Activity in Superior Colliculus
}

\author{
Tatiana Bezdudnaya and Manuel A. Castro-Alamancos \\ Department of Neurobiology and Anatomy, Drexel University College of Medicine, Philadelphia, Pennsylvania 19129
}

The superior colliculus is part of a broader neural network that can decode whisker movements in air and on objects, which is a strategy used by behaving rats to sense the environment. The intermediate layers of the superior colliculus receive whisker-related excitatory afferents from the trigeminal complex and barrel cortex, inhibitory afferents from extrinsic and intrinsic sources, and neuromodulatory afferents from cholinergic and monoaminergic nuclei. However, it is not well known how these inputs regulate whisker-related activity in the superior colliculus. We found that barrel cortex afferents drive the superior colliculus during the middle portion of the rising phase of the whisker movement protraction elicited by artificial (fictive) whisking in anesthetized rats. In addition, both spontaneous and whisker-related neural activities in the superior colliculus are under strong inhibitory and neuromodulator control. Cholinergic stimulation activates the superior colliculus by increasing spontaneous firing and, in some cells, whisker-evoked responses. Monoaminergic stimulation has the opposite effects. The actions of neuromodulator and inhibitory afferents may be the basis of the different firing rates and sensory responsiveness observed in the superior colliculus of behaving animals during distinct behavioral states.

Key words: acetylcholine; neuromodulation; norepinephrine; superior colliculus; whisker

\section{Introduction}

The superior colliculus is a well known hub for sensorimotor transformations, such as those related to orienting eye movements (saccades) in primates (Sparks and Mays, 1990; Sommer and Wurtz, 2008; Gandhi and Katnani, 2011; Krauzlis et al., 2013). Rats use rhythmic whisker movements (active whisking) to sense the environment (Carvell and Simons, 1990; Gao et al., 2001; Kleinfeld et al., 2006; Kleinfeld and Deschênes, 2011), but the role of the superior colliculus in active whisking is not well understood.

Cells in the intermediate layers of the superior colliculus are responsive to passive touch of vibrissa (i.e., deflection of stationary whiskers; McHaffie et al., 1989; Grunwerg and Krauthamer, 1990; Cohen and Castro-Alamancos, 2007; Hemelt and Keller, 2007; Cohen et al., 2008; Cohen and Castro-Alamancos, 2010a) and stimulation of the superior colliculus evokes whisker movements (McHaffie and Stein, 1982; Hemelt and Keller, 2008). A movement pattern similar to active whisking, called artificial or fictive whisking, can be produced in anesthetized rats by electrically stimulating the facial motor nerve (Zucker and Welker, 1969; Brown and Waite, 1974; Szwed et al., 2003). Using fictive whisking, we recently showed that cells in the intermediate layers of the superior colliculus are highly responsive to whisking move-

\footnotetext{
Received Jan. 30, 2014; revised April 18, 2014; accepted April 27, 2014.

Author contributions: M.A.C.-A. designed research; M.A.C.-A. and T.B. performed research; M.A.C.-A. and T.B. analyzed data; M.A.C.-A. wrote the paper.

This work was supported by the NIH.

The authors declare no competing financial interests.

Correspondence should be addressed to Dr Manuel Castro-Alamancos, Department of Neurobiology and Anatomy, Drexel University College of Medicine, 2900 Queen Lane, Philadelphia, PA 19129.

DOI:10.1523/JNEUROSCI.0444-14.2014

Copyright $\odot 2014$ the authors $\quad 0270-6474 / 14 / 347683-13 \$ 15.00 / 0$
}

ment and active touch (i.e., whisking on objects; Bezdudnaya and Castro-Alamancos, 2011). Passive-touch responses in superior colliculus are driven directly by trigeminal complex afferents and indirectly by the barrel cortex (Cohen et al., 2008). Here we address the role of the barrel cortex in driving fictive whisking responses in the superior colliculus.

In freely behaving rats, the activity and responsiveness of whisker-sensitive cells in the superior colliculus are highly dependent on the behavioral state of the animal (Cohen and CastroAlamancos, 2010c). Superior colliculus cell firing is higher during active exploration (which includes periods of active whisking) and REM sleep, compared with periods of awake immobility and slow-wave sleep. The superior colliculus appears to come online during active exploratory states and rapidly goes offline during awake immobile periods (Cohen and Castro-Alamancos, 2010 b,c). In the whisker thalamus, similar rapid modulations of whisker responsiveness and spontaneous neural activity are mediated by inhibitory inputs (Hirata et al., 2009) and neuromodulators (Castro-Alamancos, 2002a, 2004; Hirata et al., 2006). Whether this is also the case in the superior colliculus is unknown. Cells located in the intermediate layers of the superior colliculus are innervated by inhibitory afferents from local GABAergic interneurons and from extrinsic sources, such as the substantia nigra pars reticulata (Di Chiara et al., 1979; Harting et al., 1988; Redgrave et al., 1992; Kaneda et al., 2008) and zona incerta (Kim et al., 1992; Kolmac et al., 1998). Superior colliculus cells also receive cholinergic (Beninato and Spencer, 1986; Krauthamer et al., 1995; Billet et al., 1999), noradrenergic (Swanson and Hartman, 1975), and serotoninergic afferents (Steinbusch, 1981; Beitz et al., 1986). Therefore, we tested the effects of manipulating synaptic inhibition and neuromodulators (cholin- 


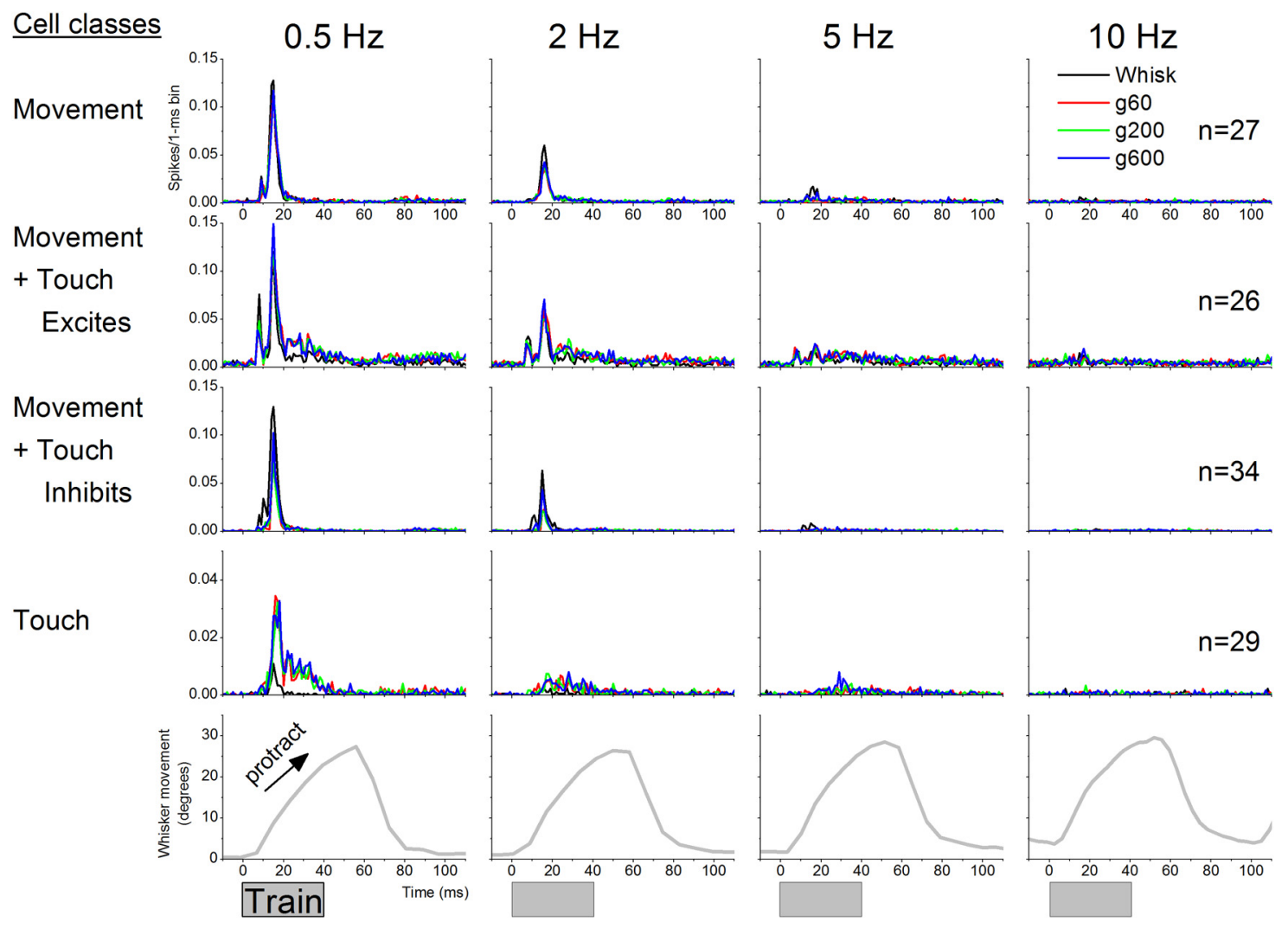

Figure 1. Population data showing four statistically defined classes of cells (single-units) in superior colliculus according to the responses evoked by fictive whisking. The four classes of cells include: (1) cells that are responsive to whisking movement only, (2) cells that are responsive to movement and active touch (whisking on a surface) excites them further, (3) cells that are responsive to movement and active touch inhibits the movement response, and (4) cells that are only responsive to active touch. Responses are shown at four different whisking frequencies during whisking in air (Whisk) and whisking on surfaces of different roughness ( $\mathrm{g} 60, \mathrm{~g} 220, \mathrm{~g} 600$ ). Bottom, The whisker movement (angle in degrees) measured with video tracking during fictive whisking (positive values indicate that the whiskers protracted). Train refers to five pulses delivered at $100 \mathrm{~Hz}$.

ergic, noradrenergic, and serotoninergic) on whisker-sensitive cells in the superior colliculus.

\section{Materials and Methods}

Fifty-seven adult male Sprague-Dawley rats (300-350 g) were used in this study and cared for in accordance with National Institutes of Health guidelines for laboratory animal welfare. All experiments were approved by the Drexel University Institutional Animal Care and Use Committee. Rats were anesthetized with urethane $(1.5 \mathrm{~g} / \mathrm{kg}$, i.p. $)$ and placed in a stereotaxic frame. All skin incisions and frame contacts with the skin were injected with lidocaine (2\%). Small craniotomies and small incisions of the dura were made over the target structures as necessary. Body temperature was automatically maintained constant with a heating pad at $37^{\circ} \mathrm{C}$. The level of anesthesia was monitored with field potential (FP) recordings and limb withdrawal reflexes and kept constant at approximately stage III/3 (i.e., slow large amplitude FP cortical oscillations, absence of pinch withdrawal reflex, absence of whisker movements) using supplemental doses of urethane.

Electrophysiology. In every case, a tungsten electrode was lowered into the depth of the barrel cortex $(0.6-1 \mathrm{~mm})$ to record multiunit activity (MUA) and FP activity. A second electrode or set of electrodes was lowered into the superior colliculus to perform single-unit or MUA and FP recordings from cells located within the following coordinates: $2-2.5 \mathrm{~mm}$ from lambda, $1.5-2.5 \mathrm{~mm}$ lateral from midline, and $3.6-5.3 \mathrm{~mm}$ in depth. These coordinates routinely yield whisker-responsive cells (Cohen et al., 2008). Single-unit recordings were obtained from high impedance (2-10 $\mathrm{M} \Omega$ ) glass electrodes filled with saline or from quartzinsulated platinum/tungsten electrodes ( $80 \mu \mathrm{m}$; shaft diameter) pulled and ground to a fine tip (3-7 M $\Omega$ ) and independently moved with a seven-channel Eckhorn system (Thomas Recording). MUA and FP recordings were obtained from tungsten electrodes (1-3 M $\Omega$ ).
Fictive whisking stimulation protocols. Fictive whisking was conducted as previously described (Bezdudnaya and Castro-Alamancos, 2011). Once unit activity was isolated in superior colliculus, a hand-held probe was used to determine the whiskers that activated the cells (receptive field). All the cells subjected to fictive whisking protocols responded to passive whisker stimulation using a hand-held probe and using an airpuff (puff) stimulus. After identification of the receptive field with the hand-held probe, puff stimulation was delivered by aiming a $2.5-\mathrm{mm}$ diameter tube 15-25 $\mathrm{mm}$ away from the receptive field (slightly elevated and facing down with a slight angle from the front toward the whiskers) so that whiskers were pushed backwards by a $50 \mathrm{~ms}$ duration puff of pressurized air (40 psi). Stimulus trials consisted of a $2 \mathrm{~s}$ period of no stimulation ( $1.5 \mathrm{~s}$ used to measure spontaneous firing) followed by 35 puffs at $0.5,2,5$, or $10 \mathrm{~Hz}$.

Puff stimulation was followed by fictive whisking in air. To trigger fictive whisking, we cut and positioned a pair of stainless steel wires in the buccal branch of the facial nerve $(0.7-1 \mathrm{~mm}$ apart), and delivered a train of five pulses (100 $\mu$ s duration) at $100 \mathrm{~Hz}$. The stimulus intensity was adjusted $\left(0.04-0.17 \mathrm{~mA}\right.$ range) to produce a protraction with a $10-35^{\circ}$ angle. In a few cases, we used synchronous video monitoring (500 frames per second; Motionscope, Red Lake Imaging) to track whisker movement frame by frame (Bezdudnaya and Castro-Alamancos, 2011). After tracking of each frame, the movements measured during each of the last 30 trains were averaged. Each train produced a whisker protraction (rising phase) that crested at $\sim 50 \mathrm{~ms}$ from the train onset, and the whiskers returned back to the starting point (falling phase) within the next $30 \mathrm{~ms}$. As per puff stimulation, each whisking in air trial consisted of a $2 \mathrm{~s}$ period of no stimulation ( $1.5 \mathrm{~s}$ used to measure spontaneous firing) followed by 35 trains at $0.5,2,5$, or $10 \mathrm{~Hz}$.

Whisking in air was followed by active touch consisting of whisking on three different surfaces. The surface was placed parallel to the rat's mid- 
A

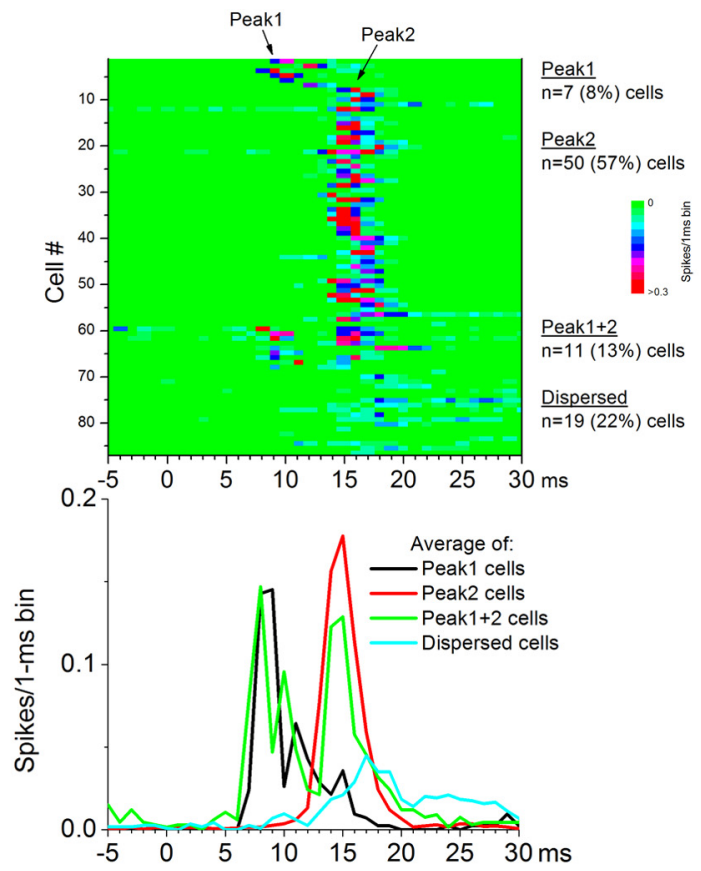

\section{B}

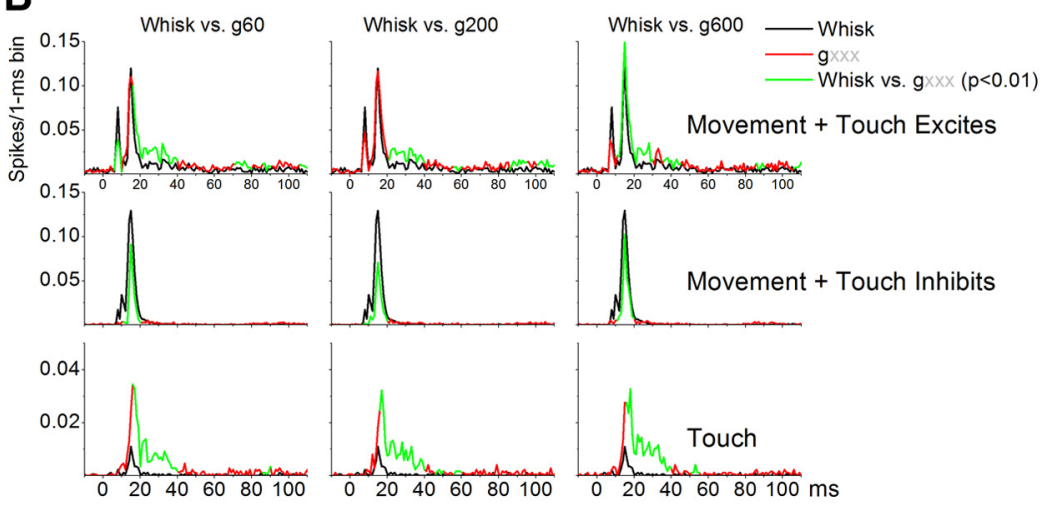

Figure 2. Whisking movement and active touch responses in superior colliculus. $A$, Whisking movement single-unit responses can be classified into four different types according to the timing of the response from whisking onset: peak1, peak2, peak $1+2$, and dispersed. Top, The color-coded plot depicts the response of each cell $(n=87)$ from the onset of the whisking movement stimulus. Bottom, Average responses for the four classes of cells shown above. $\boldsymbol{B}$, The time course from whisking onset during which active-touch responses are significantly different (larger or smaller; Wilcoxon) compared with whisking movement responses is depicted in green for the three different classes of cells that are sensitive to active touch.

line to mimic a wall that the whiskers brush against in the rostrocaudal direction. The distance from the wall to the whisker pad was adjusted to assure that most whiskers (except rostral microvibrissae, which are too short) made contact. We used three different sand paper surfaces that varied in coarseness based on grit size (g60, g220, and g600, coarse-tosmooth), and were placed on each of three sides of a rotating cube; rotating the cube $90^{\circ}$ led to the presentation of a different surface. During whisking on surfaces, the electrical stimulus and the trial setup were identical to whisking in air but the whiskers contacted the surface. Once the whisking on surfaces trials ended, all stimulus trials were repeated several times (2-5), and the data from different trials was averaged together unless otherwise stated.

Peristimulus time histograms (PSTHs), rectified MUA, and FP responses were obtained by averaging the responses to the last 30 stimuli in each 35 stimulus trial. Puff evoked responses were corrected by subtracting the time it took for the air to reach the whiskers, which was determined using a sensing piezo-electric device placed in the location of the whiskers. Stimulus artifacts created by the nerve stimulation were very distinct and easily removed. We measured the spontaneous firing rate of single-units or MUA from a $1.5 \mathrm{~s}$ period before each trial of the different stimulus types (i.e., puff, whisking in air, and whisking on surfaces). To measure single-unit evoked responses, we obtained the spike probability during a long time window $(0-100 \mathrm{~ms}$ poststimulus) or several shorter time windows within the $100 \mathrm{~ms}$ poststimulus epoch. To measure MUA evoked responses, we used both spike probability and rectified MUA. Rectified MUA evoked responses are derived by obtaining the absolute value of the MUA and then measuring the baseline corrected area during the response time window. All data are expressed as mean \pm SEM unless otherwise stated.

Single- and multi-whisker deflection protocols. Single- and multi-whisker stimulation protocols consisted of independently deflecting six individual whiskers using six different whisker stimulators (Cohen et al., 2008). After isolating unit activity, the whiskers were stimulated using a hand held probe. The whisker that produced the shortest latency and strongest response was considered the principal whisker (PW). This whisker and up to five additional whiskers surrounding it, called adjacent whiskers (AWs), were selected for stimulation (Aw1-Aw5). Each of the selected whiskers was placed in an independent whisker stimulator by inserting it into a glass micropipette $(1 / 0.5 \mathrm{~mm}$ outer diameter/inner diameter) that was glued to the membrane of a miniature speaker. Each whisker was inserted into the micropipette for $\sim 5 \mathrm{~mm}$, leaving $\sim 10$ $\mathrm{mm}$ from the end of the micropipette to the skin. Application of a $1 \mathrm{~ms}^{2}$ current pulse to the speaker deflected the micropipette and the whiskers inside. The resulting whisker deflection is a very low-amplitude $\left(\sim 2^{\circ}\right)$ and very high-velocity $\left(\sim 1000^{\circ} / \mathrm{s}\right)$ stimulus. The whisker stimulators were oriented in the preferred direction to produce the largest response as determined with the hand probe. Each of the six whisker stimulators was driven by counter/ timer boards controlled with LabVIEW software (National Instruments).

Whisker stimulation was delivered according to the following protocols. A trial consisted of an initial $2 \mathrm{~s}$ without whisker stimulation followed by stimulation delivered to each whisker at $2 \mathrm{~s}$ intervals (the order of whisker stimulation was randomly selected). The first whisker was stimulated $2 \mathrm{~s}$ after the trial began, the second whisker was stimulated $4 \mathrm{~s}$ after the trial started, and so on, so that the sixth (last) whisker stimulus was delivered $12 \mathrm{~s}$ after the start of the trial. Thus, a single trial contained stimuli for all six whiskers and lasted a total of $14 \mathrm{~s}$. Whisker stimuli consisted of 10 stimuli delivered at $10 \mathrm{~Hz}$. When all six whiskers were stimulated simultaneously (ALL), each trial lasted $5 \mathrm{~s}$. Every trial was repeated 30 times to derive PSTHs and to average FP responses. Protocols for single-whisker stimulation and simultaneous multi-whisker stimulation were combined in the same trial, so that stimulation of each individual whisker was followed ( $3 \mathrm{~s}$ after the last whisker) by stimulation of the six whiskers together in the same trial.

Microdialysis. To apply drugs into the barrel cortex or superior colliculus, a microdialysis cannula ( $250 \mu \mathrm{m}$ outer diameter, 2-mm-long membrane) was placed adjacent $(\sim 500 \mu \mathrm{m})$ to the recording electrodes in those areas. ACSF was continuously infused through the probe at $2-4$ $\mu \mathrm{l} / \mathrm{min}$ and drugs were dissolved in the ACSF. Norepinephrine (NE), carbachol (CA), physostigmine (Physo), serotonin (5HT), and fluoxetine (FLU) were used to study neuromodulation. Bicuculline (BMI) and 
CGP35348 (CGP) were used to suppress inhibition. Tetrodotoxin (TTX) and lidocaine (Lido) were used to block neural activity. To test drug effectiveness, each drug was applied at different doses during recording of local neural activity. We have used this method for several decades and typically find that the effective doses during microdialysis are $\sim 10$ times higher than during direct application in slices (Castro-Alamancos and Borrell, 1993; CastroAlamancos and Oldford, 2002; Cohen et al., 2008; Hirata and Castro-Alamancos, 2010). This is due to the fact that there is typically an $\sim 10 \%$ reverse-dialysis recovery of drugs in the extracellular medium as they dialyze down their concentration gradients across the dialysis membrane. Moreover, based on diffusion experiments using arrays of recording electrodes at different distances from the probe, we have estimated the spread to be $\sim 1 \mathrm{~mm}$ in the horizontal plane away from the membrane for the typical doses used here (Castro-Alamancos, 2000; Aguilar and Castro-Alamancos, 2005; Hirata et al., 2006).

Analysis. Statistical analyses consisted, for the most part, of paired comparisons of responses evoked in the same cells by different stimulus types (e.g., puff, whisking in air, and whisking on surfaces) and drugs. If the data were considered normally distributed, according to the Shapiro-Wilk normality test, we used parametric statistics. For two groups, we used the $t$ test (paired or independent). For more than two groups, we tested for a significant main effect using the repeated-measures ANOVA followed by comparisons with Tukey's test. If the data were considered not normally distributed, we used nonparametric statistics consisting of the Wilcoxon signed ranks (paired comparisons). When performing multiple comparisons (Wilcoxon), $p$ values were adjusted using a Bonferroni correction by multiplying the $p$ value by the number of comparisons made. The $\alpha$ level used for significance was $p<0.05$ or $p<0.01$ as indicated.

Histology. At the end of the experiments, animals were killed with an overdose of pentobarbital and the brain was rapidly removed and placed in fixative (4\% paraformaldehyde). In some cases, coronal sections (100 $\mu \mathrm{m}$ ) of the superior colliculus were obtained using a vibratome, and these were stained with cresyl violet. Based on coordinates, electrode tracks, and lesions made to mark the recording sites $(0.02 \mathrm{~mA}$ constant current, $10 \mathrm{~s}$ duration; twice), the cells were located in the intermediate layers of the superior colliculus.

\section{Results}

\section{Fictive whisking responses in superior colliculus}

During fictive whisking, the brain does not generate a motor command or the corresponding efference copy. Instead, it receives a signal that reflects the movement imposed by the electrical stimulation of the motor nerve. This movement signal (reafference) is caused by some trigeminal ganglion cells that discharge during fictive whisking in air (without object contact; Szwed et al., 2003); more dispersed and less phase-locked ganglion cell discharges appear to occur during natural whisking in air in behaving animals (Khatri et al., 2009). While keeping these differences in mind, fictive whisking is a useful model to investigate whisker-evoked responses in neural circuits under highly controlled conditions that enable sophisticated experimental procedures that are technically difficult or unfeasible in freely moving animals.
In urethane-anesthetized rats, we recorded single-unit responses in the intermediate layers of the superior colliculus and FP responses in the barrel cortex during air-puff stimulation of stationary whiskers (passive touch), fictive whisking in air (whisking movement), and fictive whisking on three different surfaces varying in texture (active touch) as if the rat was brushing its whiskers on an adjacent wall.

The cells were determined to be responsive to whisker stimulation by a hand held probe and by an air-puff stimulus delivered at low-frequency $(0.5 \mathrm{~Hz})$ aimed at the receptive field (i.e., whiskers that were determined to drive the cell using a hand-held probe). Puff stimulation was followed by fictive whisking in air (whisk) and whisking on three surfaces (g60, g220, g600) at 0.5, 2, 5 , and $10 \mathrm{~Hz}$. As shown in Figure 1 (bottom), the whisker movement associated with fictive whisking in air consisted of a protraction with a rising phase and a falling phase. The rising phase crested at $\sim 50 \mathrm{~ms}$, after which the protraction returned to baseline within the next $\sim 30 \mathrm{~ms}$.

To determine whether a cell was sensitive to a particular stimulus type (delivered at $0.5 \mathrm{~Hz}$ ), we performed paired statistical comparisons (Wilcoxon; see Materials and Methods) between the evoked response (measured $0-100 \mathrm{~ms}$ after the stimulus) and the spontaneous firing (measured $100 \mathrm{~ms}$ before the stimulus) for every trial. To determine whether a cell was more sensitive to a particular stimulus type than another, we also compared the responses between the different stimulus types. Based on these comparisons, we found four main statistically determined classes of cells (Fig. 1). First, 23\% of the cells respond to fictive whisking 


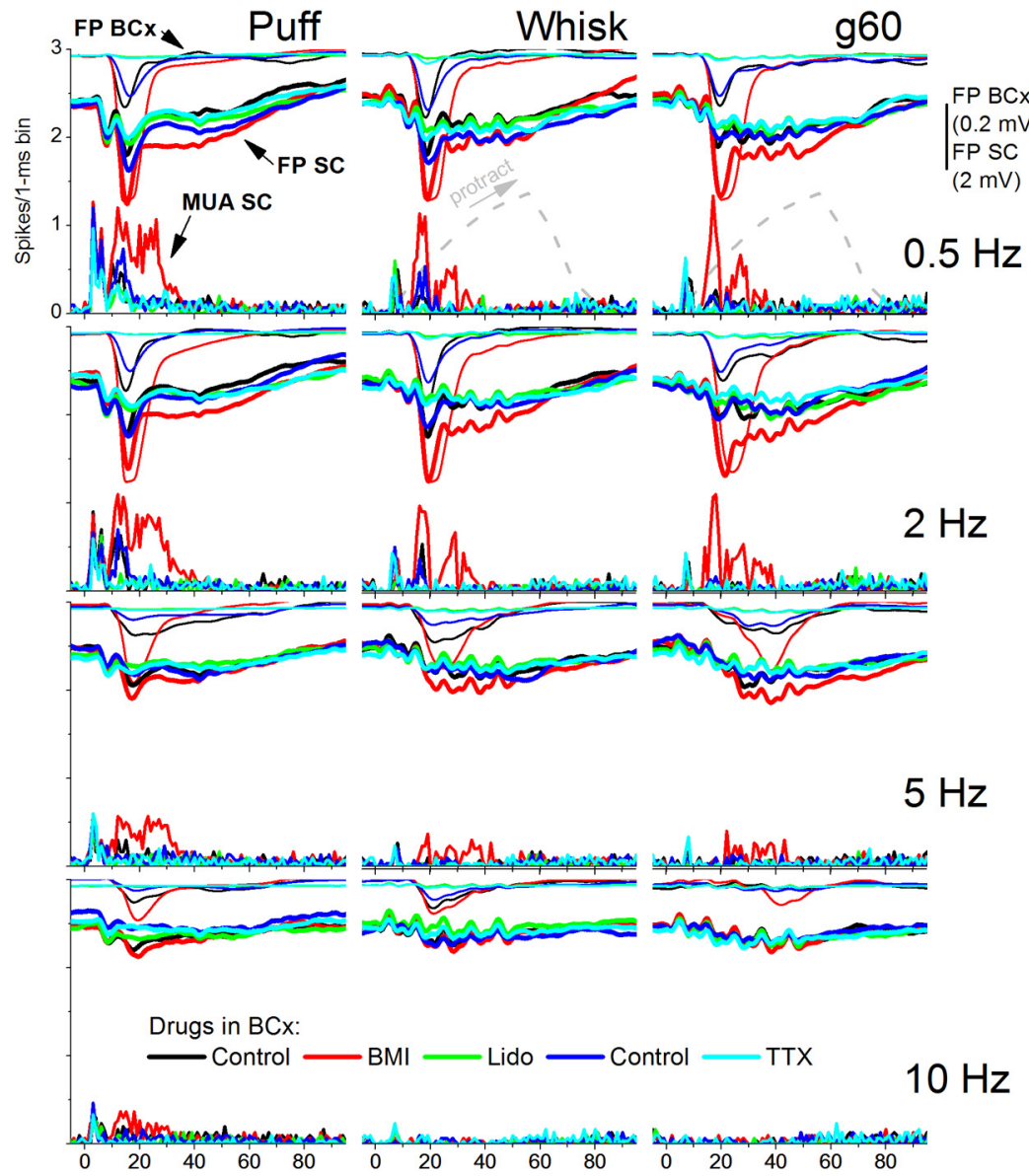

Figure 4. Another example showing the effect of barrel cortex response enhancement and suppression on superior colliculus responses driven by fictive whisking at four different frequencies $(0.5,2,5$, and $10 \mathrm{~Hz})$. FP responses recorded in the barrel cortex ( $B C x$; thin traces, top) and superior colliculus (SC; thick traces, bottom) evoked by passive touch (puff), whisking movement (whisk), and active touch (g60) during control (black), application of BMl in barrel cortex to enhance the evoked response (red), during application of Lido in barrel cortex to suppress the evoked response (green), during recovery from the effects of lidocaine in barrel cortex (blue), and during subsequent application of TTX in barrel cortex (light blue). Note that peak2 responses in superior colliculus are enhanced and suppressed in unison with corresponding changes in the barrel cortex response. mostly between 5 and $20 \mathrm{~ms}$. The time course of these responses roughly coincides with the two peaks evoked in superior colliculus by passive touch stimuli (mechanical whisker deflections), which we have previously called peak 1 (3-12 ms) and peak2 (12-20 ms) and are caused by trigeminotectal and corticotectal inputs, respectively (Cohen et al., 2008). Among our cell population that responds to fictive whisking in air $(n=87 ; 75 \%$ of all the cells), we found four classes of cells according to the timing of the response from the onset of the whisking movement (Fig. $2 A)$. A small group of cells ( $8 \%)$ had a single peak response before $12 \mathrm{~ms}$, and we call them peak 1 cells. The majority of cells (57\%) had a single peak response between 12 and $20 \mathrm{~ms}$, and we call these peak 2 cells. A third group of cells (13\%) had both a peak 1 and a peak 2 response, and we call them peak $1+2$ cells. Finally, a fourth group of cells $(22 \%)$ had a dispersed response to fictive whisking in air. In conclusion, the majority ( $\sim 70 \%)$ of cells that respond to whisking movement in superior colliculus have a peak2 (12-20 ms) response, which as we will see below is mainly driven by corticotectal inputs.

\section{Active-touch responses}

As noted above (Fig. 1) there are three effects of active touch on superior colliculus responses. Whisking on a surface can enhance or suppress the response to whisking movement, or it can generate a significant response in cells that respond poorly to whisking movement. To determine the time course of these effects, we in air but are unaffected by active touch (movement cells; Fig. 1, first row). These movement cells respond to the whisking movement during the early part of the rising phase of the protraction, and the response is unaffected by touching a surface during the movement. Second, $22 \%$ of the cells also respond to fictive whisking in air but touching a surface increases the response evoked by the whisking movement (movement + touch excites; Fig. 1, second row). Third, $29 \%$ of the cells respond to fictive whisking in air but touching a surface decreases the response evoked by the whisking movement (movement + touch inhibits; Fig. 1, third row). Fourth, $25 \%$ of the cells have negligible (statistically nonsignificant) responses to fictive whisking in air (insensitive to movement) but touching a surface produces robust responses (touch cells; Fig. 1, fourth row). These touch responses occur as the whiskers brush the surface during the protraction. For all cell types, the responses are mostly apparent at low frequencies and display very strong adaptation at higher frequencies; responses are virtually abolished at $10 \mathrm{~Hz}$. It is worth considering that some of the cells may not have respond to touch because their angular selectivity was not engaged by the surface.

\section{Whisking movement responses}

Fictive whisking in air responses are driven by the whisker movement and occur only during the onset of the whisker protraction, performed paired comparisons per $1 \mathrm{~ms}$ bin between fictive whisking in air and whisking on a surface for the three groups of cells that respond to active touch. Figure $2 B$ shows (in green) the section of the response evoked by active touch that is statistically significantly different from the whisking movement response (in black). For cells in which touch excites, the enhancement mainly occurred between 15 and 40 ms. For cells in which touch inhibits, the suppression was more focused and occurred earlier between 10 and $20 \mathrm{~ms}$. Finally, the response of cells that are sensitive to active touch, but not to whisking movement, occurs between 15 and $40 \mathrm{~ms}$. In conclusion, active-touch responses in superior colliculus occur mainly during a $15-40 \mathrm{~ms}$ time window that coincides with the middle portion of the rising phase of the protraction as whiskers brush the surface.

\section{Impact of barrel cortex on fictive whisking responses in superior colliculus}

Passive-touch (mechanical whisker deflections of stationary whiskers) neural responses in superior colliculus are distinctive driven respectively by direct trigeminotectal inputs from the trigeminal complex followed by corticotectal inputs from the barrel cortex (Cohen et al., 2008; Cohen and Castro-Alamancos, 2010c). Peak1 responses are unaffected by barrel cortex manipuand consist of two successive peaks, called peak1 and peak2, 
lations, whereas peak2 responses are enhanced or suppressed by enhancing or suppressing barrel cortex responses, respectively. Using similar methods as in our previous passive touch work, we tested the impact of enhancing or suppressing barrel cortex responses on superior colliculus responses evoked by fictive whisking. Figure 3 shows two experiments in which drugs were applied in the barrel cortex via microdialysis to enhance or suppress barrel cortex responses to determine the effect on superior colliculus responses. Figure $3 A$ displays FP responses from both barrel cortex (thin traces) and superior colliculus (thick traces). Figure $3 B$ displays $\mathrm{FP}$ responses from barrel cortex and MUA responses from superior colliculus. Control responses (black traces) were evoked by a puff, fictive whisking in air, and whisking on surfaces (only g60 is shown in Fig. 3).

During application of a low dose of a $\mathrm{GABA}_{\mathrm{A}}$ receptor antagonist (BMI $10 \mu \mathrm{M}$; red traces) into the barrel cortex, the short-latency response in barrel cortex (peakA), caused by puff or whisking, was robustly enhanced. At the same time, the peak2 response (12-40 $\mathrm{ms}$ ) in the superior colliculus was robustly enhanced for both FP and MUA recordings. Importantly, the peak1 response (3-12 $\mathrm{ms})$ in superior colliculus was not significantly affected by peakA enhancement caused by BMI in barrel cortex. It is also worth noting that this dose of BMI delivered via microdialysis enhances the evoked response but does not lead to spontaneous epileptiform discharges (Castro-Alamancos and Borrell, 1995; CastroAlamancos, 1999, 2000). Subsequent application of Lido (10$20 \%$; green traces) into the barrel cortex leads to a complete suppression of peakA responses in barrel cortex. At the same time, peak2 responses in superior colliculus were strongly suppressed, whereas peak1 responses were little affected.

The effect of lidocaine was rapidly reversible upon removing it from barrel cortex. This recovery is demonstrated in another experiment shown in Figure 4 (ACSF; blue traces), which shows FP responses recorded in barrel cortex and both FP and MUA responses recorded in superior colliculus for all stimulus protocols and drug conditions. During washout of lidocaine with ACSF, barrel cortex peakA responses and superior colliculus peak2 responses returned to control levels. Furthermore, subsequent application of TTX (10 $\mu \mathrm{M}$; cyan traces) into the barrel cortex had an effect similar to lidocaine. Due to the strong adaptation of responses at higher frequencies, the effects of barrel cortex response suppression or enhancement on superior colliculus responses were more obvious at low frequencies, when responses are larger (unadapted) in both areas.

Figure 5 shows measurements of FP and MUA responses evoked in superior colliculus by puff and whisking (in air and on surfaces) from the population of experiments $(n=10)$ in which we tested the effects of BMI and lidocaine applied into the barrel cortex. Figure $5 A, B$ shows the amplitude of peak1 (3-12 ms) and peak2 (12-25 ms) FP responses measured in superior colliculus during control, BMI and Lido. It is important to note that FP peak 1 and peak 2 responses in Figure $5 A, B$ are measured from the prestimulus baseline; note that peak 2 responses ride on the peak 1 response (Figs. 3, 4). As shown in the examples, very little peak2 FP responses remain in superior colliculus after application of lidocaine in barrel cortex, whereas peak 1 is unaffected. The spontaneous activity (MUA) of superior colliculus cells did not change significantly during application of either BMI or Lido into neocortex (Tukey; $n=10$; n.s.), but peak 2 responses were significantly affected. To measure evoked responses, we rectified the raw MUA and measured the area of the responses from the prestimulus baseline. Figure 5C,D shows peak1 (3-12 ms) and peak2 (12-21 ms) responses measured in superior colliculus during control, BMI and lidocaine. The results show that peak1 (FP or MUA) responses in superior colliculus were not significantly affected by application of either BMI or Lido in barrel cortex. However, MUA peak2 responses were significantly enhanced by application of BMI and suppressed by application of Lido in barrel cortex. As shown in Figure 5, significant effects were observed mostly during low-frequency stimuli $(0.5-5 \mathrm{~Hz})$; not during high-frequency stimuli $(10 \mathrm{~Hz})$ when responses are already strongly adapted. Thus, similar to passive touch responses, peak1 movement and active touch responses in superior colliculus are driven by trigeminotectal inputs, whereas peak 2 responses are driven by corticotectal inputs.

\section{Synaptic inhibition controls spontaneous firing and fictive whisking responses in superior colliculus}

Intracellular recordings in the superior colliculus in vivo show that passive-touch responses produce excitatory and IPSPs (Cohen et al., 2008). IPSPs in superior colliculus originate from inhibitory interneurons within superior colliculus, and from 

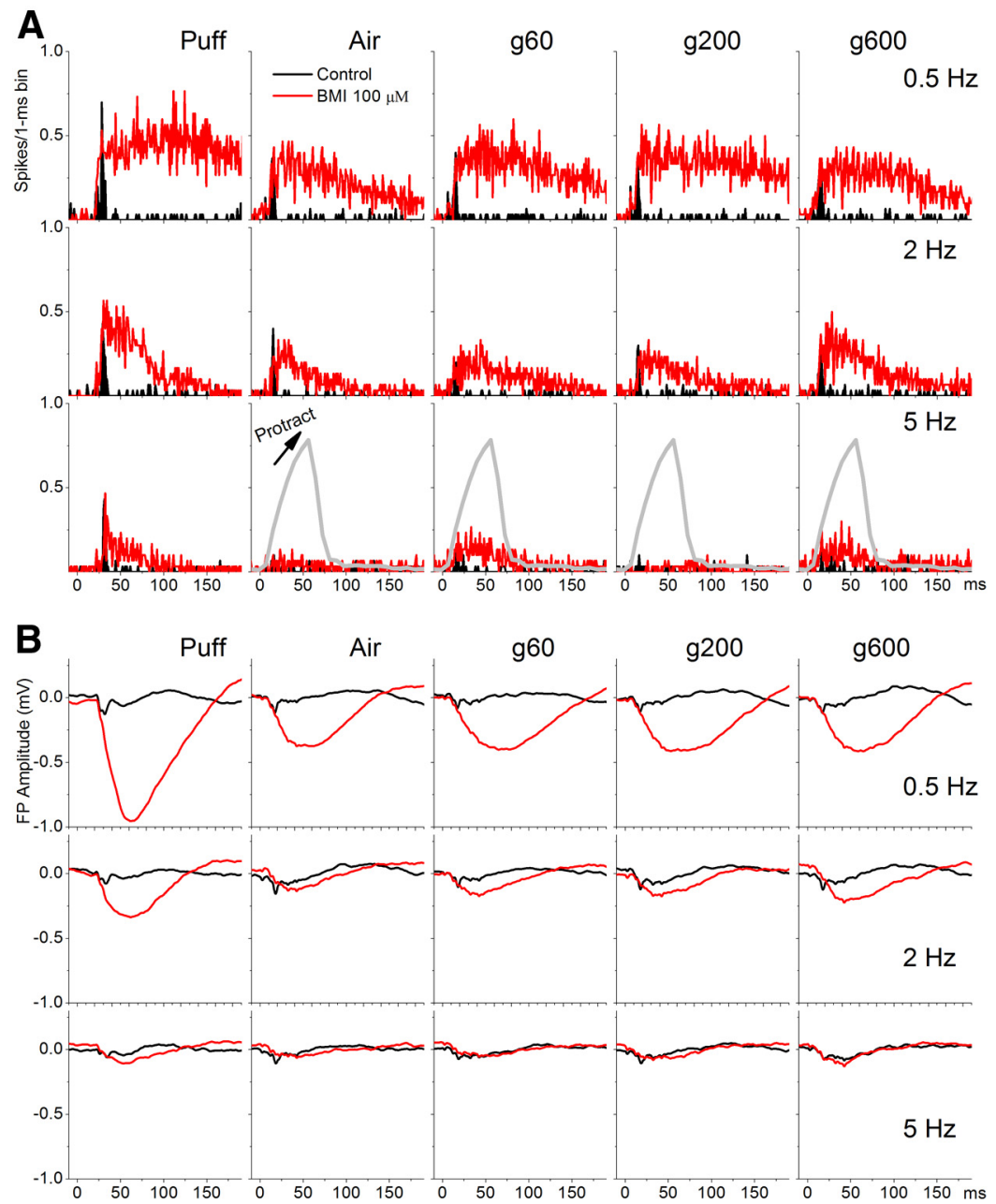

Figure 6. Example showing the effect of blocking $\mathrm{GABA}_{\mathrm{A}}$ receptors in superior colliculus on superior colliculus responses driven by fictive whisking. A, PSTH of unit activity evoked in superior colliculus by passive touch (puff), whisking movement (whisk), and active touch ( $g 60, g 200, g 600)$ during control (black) and during application of BMl in superior colliculus (red). Note the large enhancement of evoked responses during block of inhibition. $\boldsymbol{B}$, Same as $\boldsymbol{A}$, but FP responses recorded in superior colliculus are shown.

substantia nigra pars reticulata and zona incerta afferents (Isa and Hall, 2009). To determine whether spontaneous firing and the fictive whisking responses in superior colliculus are suppressed by GABA mediated inhibition we used a method we have used before in ascending thalamocortical pathways (Hirata et al., 2009) that consists in blocking inhibition to unmask the excitatory responses and spontaneous activities that are normally suppressed by inhibition. We used microdialysis to infuse a $\mathrm{GABA}_{\mathrm{A}}$ receptor antagonist $(\mathrm{BMI})$ followed by a $\mathrm{GABA}_{\mathrm{B}}$ receptor antagonist (CGP35348) directly into the superior colliculus. At the same time, we measured MUA and FP responses evoked by fictive whisking in both the superior colliculus (adjacent to the microdialysis probe) and in the barrel cortex. The barrel cortex activity served as a control for stability during changes observed in the superior colliculus.

Figure 6 shows a typical example of the effect of BMI (100 $\mu \mathrm{M})$ infused into the superior colliculus. BMI produced a robust enhancement of all evoked responses including puff, whisking in air, and whisking on surfaces. The enhancement of the evoked responses was observed in both MUA (Fig. 6A) and FP (Fig. 6B) recordings in superior colliculus, with no significant change in barrel cortex (data not shown). For fictive-whisking responses, the response enhancement was strongest during the whisker movement up to 100 ms (protraction-retraction), declining thereafter. Application of BMI also had a significant effect on spontaneous firing as expected from the notion that substantia nigra pars reticulata afferents keep superior colliculus cells under tight inhibitory control. Figure $7 A$ shows the effect of different doses of BMI on spontaneous firing in superior colliculus. Subsequent application of a $\mathrm{GABA}_{\mathrm{B}}$ receptor antagonist (CGP35348, 5 mm) during $\mathrm{GABA}_{\mathrm{A}}$ receptor blockade (BMI) also produced a relatively small but significant enhancing effect on spontaneous firing (Fig. 7A). Thus, the spontaneous firing of whiskersensitive superior colliculus cells is controlled by inhibition, particularly $\mathrm{GABA}_{\mathrm{A}}$ mediated inhibition.

Figure $7 B$ shows population data of evoked responses (rectified MUA) measured during a 3-100 ms window poststimulus evoked by each of the stimulus types at the four different frequencies before (control) and during disinhibition (BMI + CGP35348; $100 \mu \mathrm{M}+5 \mathrm{~mm})$. It is worth noting that block of $\mathrm{GABA}_{\mathrm{A}}$ receptors alone produced the same effect as blocking both $\mathrm{GABA}_{\mathrm{A}}$ and $\mathrm{GABA}_{\mathrm{B}}$ receptors (data not shown); in other words, subsequent block of $\mathrm{GABA}_{\mathrm{B}}$ receptors after block of $\mathrm{GABA}_{\mathrm{A}}$ receptors did not have any additional significant effects on the measured evoked responses. The main effect of disinhibition was to enhance sensory responses evoked by low-frequency stimulation $(0.5 \mathrm{~Hz})$, but much less those evoked by higher-frequencies (only puff responses were significantly enhanced at higher-frequencies; 2 and $5 \mathrm{~Hz}$ ). This implies that rapid-sensory adaptation in superior colliculus is for the most part not caused by feedforward synaptic inhibition, which is similar to previous results obtained in the whisker thalamus (Castro-Alamancos, 2002a; Hirata et al., 2009).

These results indicate that synaptic inhibition keeps whiskersensitive superior colliculus cells under tight control, which is consistent with previous studies (Harting et al., 1988; Redgrave et al., 1992; Kaneda et al., 2008). Spontaneous firing and lowfrequency evoked responses (movement and active touch) are normally strongly dampened by inhibition. Rapid sensory adaptation of high-frequency passive- or active-touch responses is not due to GABA-mediated inhibition.

\section{Neuromodulators influence passive touch multi-whisker responses in superior colliculus}

To determine the impact of neuromodulators on whiskersensitive cells, we used microdialysis to infuse the cholinergic agonist CA (0.1-1 mM), NE (0.1-1 mM) or 5HT (0.1-1 mM) into the superior colliculus while recording MUA or single-units in the intermediate layers. This was done in two groups of experiments. In the first set of experiments, we determined the effect of CA and NE on superior colliculus responses evoked by single- 
A

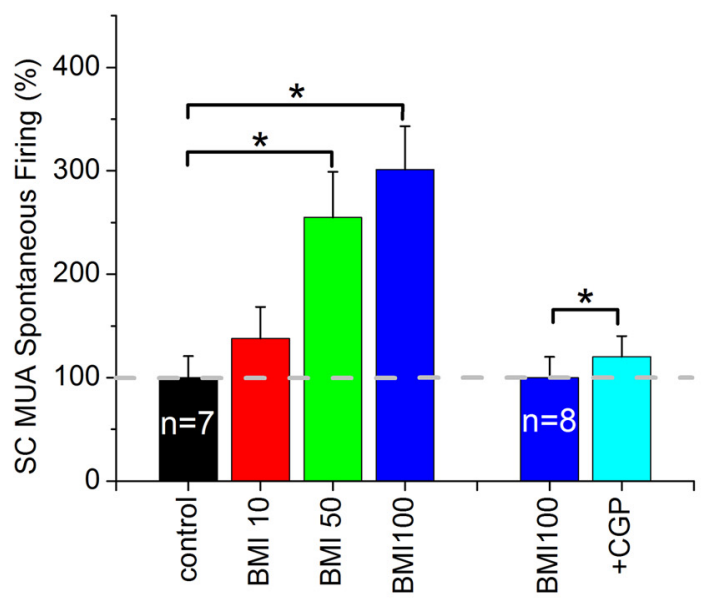

B

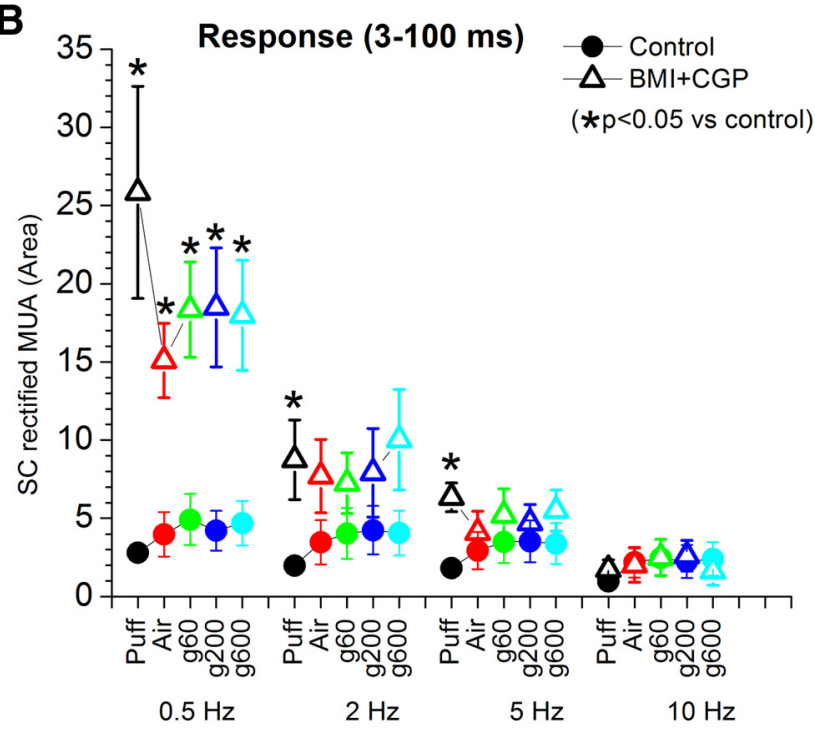

Figure 7. Population data measuring the effect of superior colliculus disinhibition on superior colliculus spontaneous firing and responses driven by fictive whisking. $A$, Effect of block of $G A B A_{A}$ receptors with $B M l$ at different doses on spontaneous firing. Also shown is the effect on spontaneous firing of blocking $G_{A B A_{B}}$ receptors during $G_{A B A_{A}}$ receptor block. *Statistical differences (Tukey, $p<0.05$ ) between the groups. $B$, Area of rectified MUA responses (3-100 ms) driven by fictive whisking measured from the prestimulus baseline in superior colliculus during control (closed circles) and during disinhibition (open triangles). ${ }^{*}$ Statistical differences (Tukey) between the groups.

whisker and multi-whisker deflections of stationary whiskers. In the second group of experiments, we determined the effect of CA, $\mathrm{NE}$, and $5 \mathrm{HT}$ on superior colliculus responses evoked by fictive whisking.

Whisker-sensitive cells in the superior colliculus typically respond poorly to single-whisker deflections but respond robustly to simultaneous, or nearly simultaneous, multi-whisker stimulation with a characteristic peak1(trigeminotectal) followed by peak2 (corticotectal) response. Intracellular and FP recordings reveal subthreshold postsynaptic potentials evoked by singlewhisker deflections that sum to trigger action potentials during multi-whisker deflections (Cohen et al., 2008). Thus, we first used FP recordings to determine the impact of CA and NE on single-whisker and multi-whisker subthreshold responses. Figure $8 A-D$ shows the effect of these drugs on multi-whisker responses evoked by simultaneously deflecting six whiskers (ALL) at 0.1 or $10 \mathrm{~Hz}$. Also shown are the responses evoked by deflecting (at $0.1 \mathrm{~Hz}$ ) the PW or the strongest adjacent whisker (AW1)
A
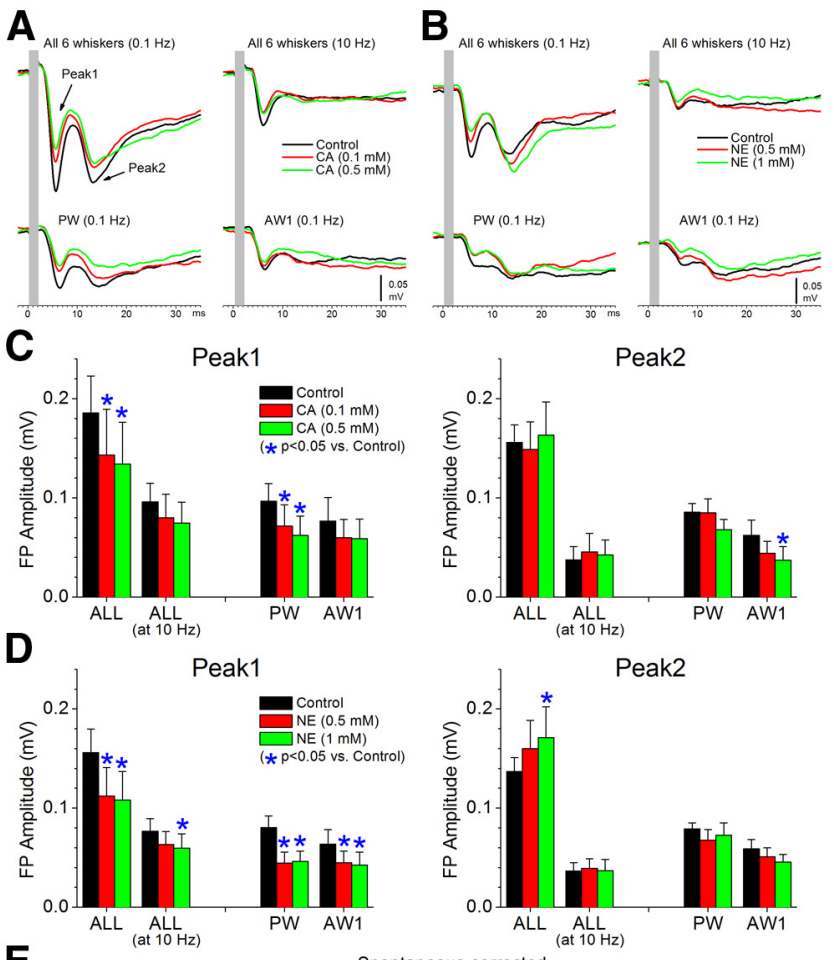

E

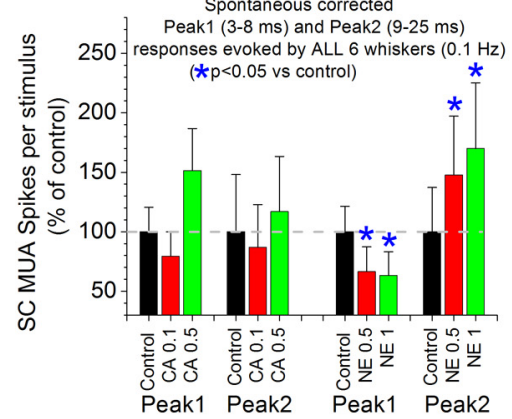

Figure 8. Effect of neuromodulators applied in superior colliculus on single-whisker and multi-whisker responses evoked by deflection of stationary whiskers. $\boldsymbol{A}, \boldsymbol{B}$, Examples of the effects of $C A(\boldsymbol{A})$ and NE $(\boldsymbol{B})$ on peak1 and peak 2 FP responses evoked by simultaneous multiwhisker deflection of six whiskers (ALL) at 0.1 or $10 \mathrm{~Hz}$, single-whisker stimulation of the PW and single-whisker stimulation of the adjacent whisker producing the strongest response (AW1) at $0.1 \mathrm{~Hz}$. Two different doses of each drug are shown. C, Population data measuring the effect of $C A(n=8)$ on peak1 (left) and peak2 (right) responses evoked by ALL at 0.1 and $10 \mathrm{~Hz}$, and PW and AW1 deflections at $0.1 \mathrm{~Hz}$. * Statistical differences (Tukey) between the groups. $\boldsymbol{D}$, Population data measuring the effect of $\mathrm{NE}(n=12)$ on peak1 (left) and peak2 (right) responses evoked by ALL at 0.1 and $10 \mathrm{~Hz}$, and PW and AW1 deflections at $0.1 \mathrm{~Hz}$. *Statistical differences (Tukey) between the groups. $\boldsymbol{E}$, Population data measuring the effect of CA (left) and NE (right) on peak1 and peak2 MUA responses evoked by ALL at $0.1 \mathrm{~Hz}$. Responses were corrected by subtracting the spontaneous firing. *Statistical differences (Tukey) between the groups.

among the sixwhiskers. Low-frequency $(0.1 \mathrm{~Hz})$ multi-whisker deflections produce robust peak1 (peaking at $5.7 \pm 0.2 \mathrm{~ms} ; n=$ $12)$ and peak2 $(13.2 \pm 0.5 \mathrm{~ms})$ responses. These responses are much smaller (Fig. 8) and delayed during high-frequency $(10 \mathrm{~Hz})$ stimulation $(6.4 \pm 0.4$ and $15.4 \pm 0.6 \mathrm{~ms})$ and during lowfrequency single-whisker stimulation $(6.7 \pm 0.3$ and $14.2 \pm 0.5$ ms for the PW). Low-frequency AW2-AW5 and high-frequency single-whisker responses were not measured because they are too weak.

We found that CA $(0.1-0.5 \mathrm{~mm} ; n=8)$ and NE $(0.5-1 \mathrm{~mm}$; $n=12$ ) depressed peak1 FP responses evoked by low-frequency multi-whisker or single-whisker deflections. The depressing effect of NE on single-whisker responses was more consistent than 

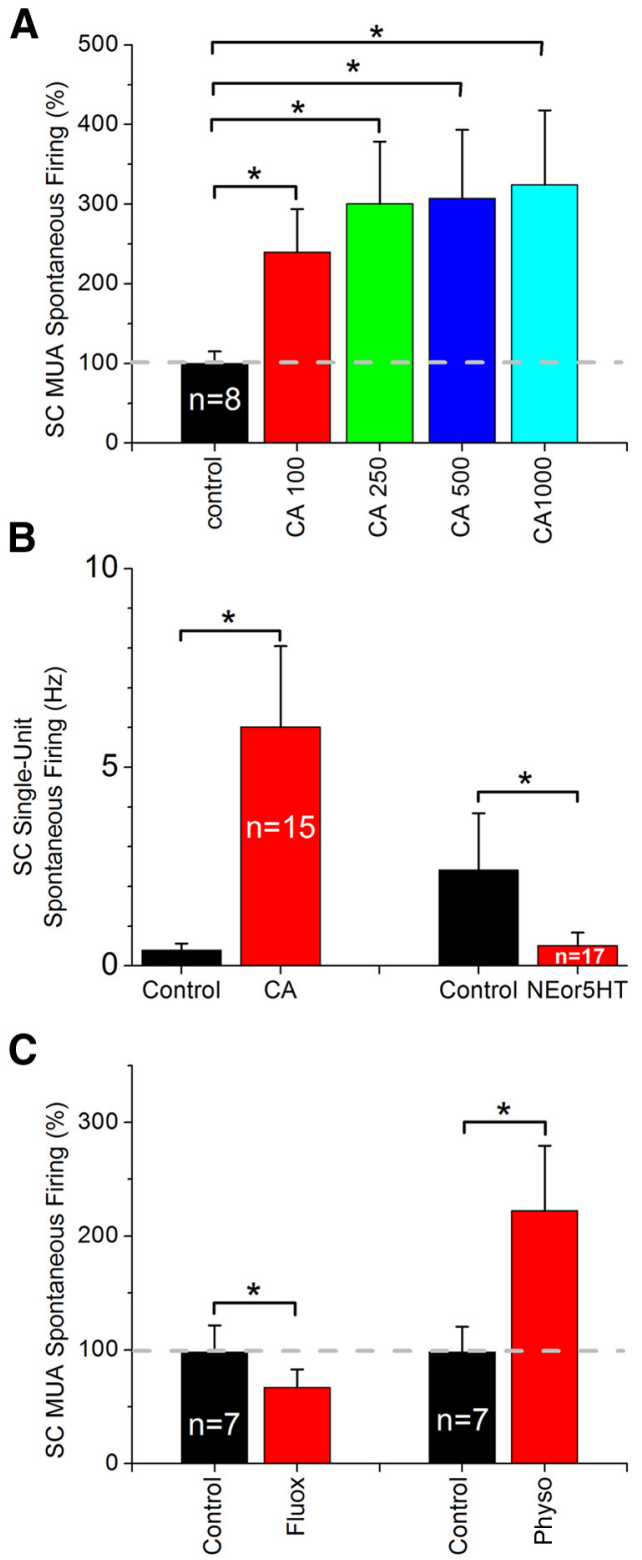

Figure 9. Population data measuring the effect of neuromodulators applied in superior colliculus on spontaneous MUA and single-unit activity in superior colliculus. $A$, Effect of different doses of $C A$ (in $\mu \mathrm{m}$ ) on MUA spontaneous firing. * Statistical differences (Tukey, $p<0.05$ ) between the groups. $\boldsymbol{B}$, Effect of $\mathrm{CA}(0.5 \mathrm{~mm})$ and $\mathrm{NE}(0.5 \mathrm{~mm})$ or $5 \mathrm{HT}(0.5 \mathrm{~mm})$ on single-unit spontaneous firing (NE and 5HTdata are pooled together). Note that to test the effect of NE or $5 \mathrm{HT}$ we selected cells with significant spontaneous firing during control. *Statistical differences (paired $t$ test, $p<0.05)$ between the groups. C, Effect of fluoxetine $(1.8 \mathrm{~mm})$ and Physo $(5 \mathrm{~mm})$ on MUA spontaneous firing. * Statistical differences (Wilcoxon, $p<0.05$ ) between the groups.

that of CA; reaching statistical significance for both the PW and AW1. In contrast, these drugs did not suppress peak2 FP responses evoked by multi-whisker stimulation. In fact, NE significantly enhanced peak 2 responses at the largest dose (Fig. $8 D$, right). These results indicate that trigeminotectal (peak1) and corticotectal (peak2) inputs evoked by simultaneous multiwhisker deflections are differentially regulated by neuromodulators. Trigeminotectal subthreshold responses are suppressed by either CA or NE, whereas corticotectal subthreshold responses are unaffected by CA and enhanced by NE.

We next measured the effects of these neuromodulators on MUA (suprathreshold) recorded through the same electrodes as the FP data. Because suprathreshold responses evoked by singlewhisker stimulation are too small, we measured the effects of these drugs only on low-frequency multi-whisker responses. As discussed below in more detail, we noticed that CA enhanced spontaneous firing, whereas NE suppressed spontaneous firing. Therefore, when measuring MUA peak 1 and peak 2 responses, we subtracted the spontaneous firing measured during an equivalent response window before the whisker deflection (Fig. $8 E$ ). We found that CA and NE differentially affected MUA responses. Similar to the subthreshold FP effects, NE significantly suppressed the peak 1 and enhanced peak 2 MUA responses indicating a different modulation of trigeminotectal and corticotectal inputs. In contrast to the subthreshold FP effects, CA did not significantly suppress peak1 MUA responses evoked by lowfrequency multi-whisker stimulation; in fact, CA tended to enhance these responses at the highest dose (Tukey, $p=0.05$ ). The different effects of CA on subthreshold (FP) and suprathreshold (MUA) multi-whisker responses is likely related to the robust enhancement of spontaneous firing produced by cholinergic activation, as described below.

\section{Neuromodulators control spontaneous firing in superior colliculus}

Using both MUA and single-unit recordings we determined the effect of these drugs on spontaneous firing. CA has a fairly consistent effect on spontaneous firing of MUA $(n=8 ; 0.1-1 \mathrm{mM}$; Fig. $9 A)$ and single-units $(n=15 ; 0.5 \mathrm{~mm}$; Fig. $9 B)$. CA significantly enhanced the firing rate of whisker sensitive cells in superior colliculus starting with the lowest dose $(0.1 \mathrm{~mm})$ tested. Single-units were either not significantly affected by CA ( 7 of 15 cells) or the firing rate increased significantly ( 8 of 15 cells). The effect of CA resembled that of disinhibition (BMI + CGP; Fig. 7), perhaps because both act by suppressing synaptic inhibition. Therefore, we tested whether the effect of CA $(0.5 \mathrm{~mm})$ would still be present during disinhibition (BMI + CGP35348; 0.1 + $5 \mathrm{mM}$ ). The results show that during disinhibition the effect of CA on MUA spontaneous firing was much smaller than during control conditions. During control, CA (0.5 mM) enhanced MUA spontaneous firing by twofold (201.17 $\pm 42 \%$; Fig. $9 A)$, whereas during disinhibition CA only enhanced spontaneous firing by $24.1 \pm$ $20 \%$ (Wilcoxon, $p=0.02 ; n=8$ ). Thus, most of the effect of CA on spontaneous firing seems to require intact inhibition, suggesting that CA produces its enhancing effect on spontaneous firing by disinhibiting the superior colliculus. Finally, we tested whether the effect of CA on spontaneous firing could be reproduced by increasing the endogenous levels of acetylcholine by applying Physo, an acetylcholinesterase inhibitor, into the superior colliculus. This has previously been effective in barrel cortex (Oldford and Castro-Alamancos, 2003). Indeed, similar to the effect produced by CA, Physo $(5 \mathrm{~mm})$ resulted in a significant increase in MUA spontaneous firing (Fig. 9C; $n=7$ ).

In contrast to CA, NE suppressed MUA spontaneous firing at the highest doses tested (Wilcoxon, $p=0.005 ; 0.5-1 \mathrm{~mm} ; n=5$ ) but not at the lowest doses (Wilcoxon, $p=0.7 ; 0.1-0.25 \mathrm{~mm} ; n=$ 5). A few experiments with 5HT $(n=3)$ also resulted in similar suppressions of spontaneous MUA at similar doses. Therefore, we tested the effects of either NE $(0.5 \mathrm{~mm})$ or $5 \mathrm{HT}(0.5 \mathrm{~mm})$ on single-units that had some spontaneous firing during control. Together the results show that cells that have spontaneous firing are significantly suppressed by either NE or 5HT (paired $t$ test, $p=0.01 ; n=17$ cells; Fig. 9D); the results from NE and 5HT cells were combined because the effects were similar and because only a few of the cells had some spontaneous firing so that a suppres- 
A
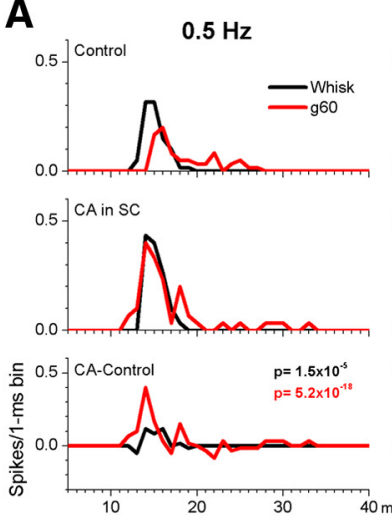

C
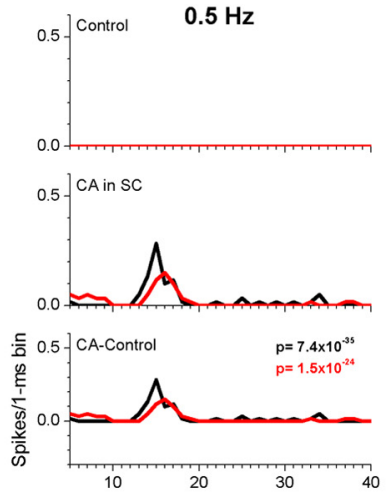

$5 \mathrm{~Hz}$
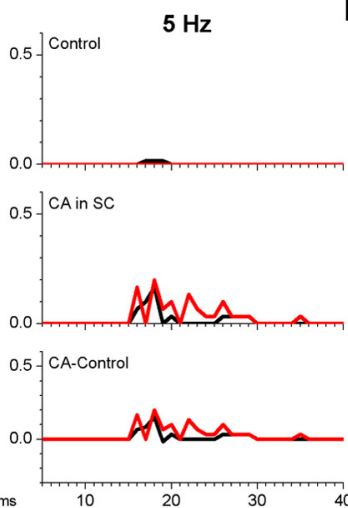

B
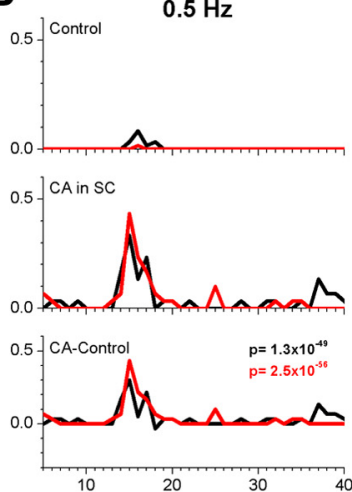

D
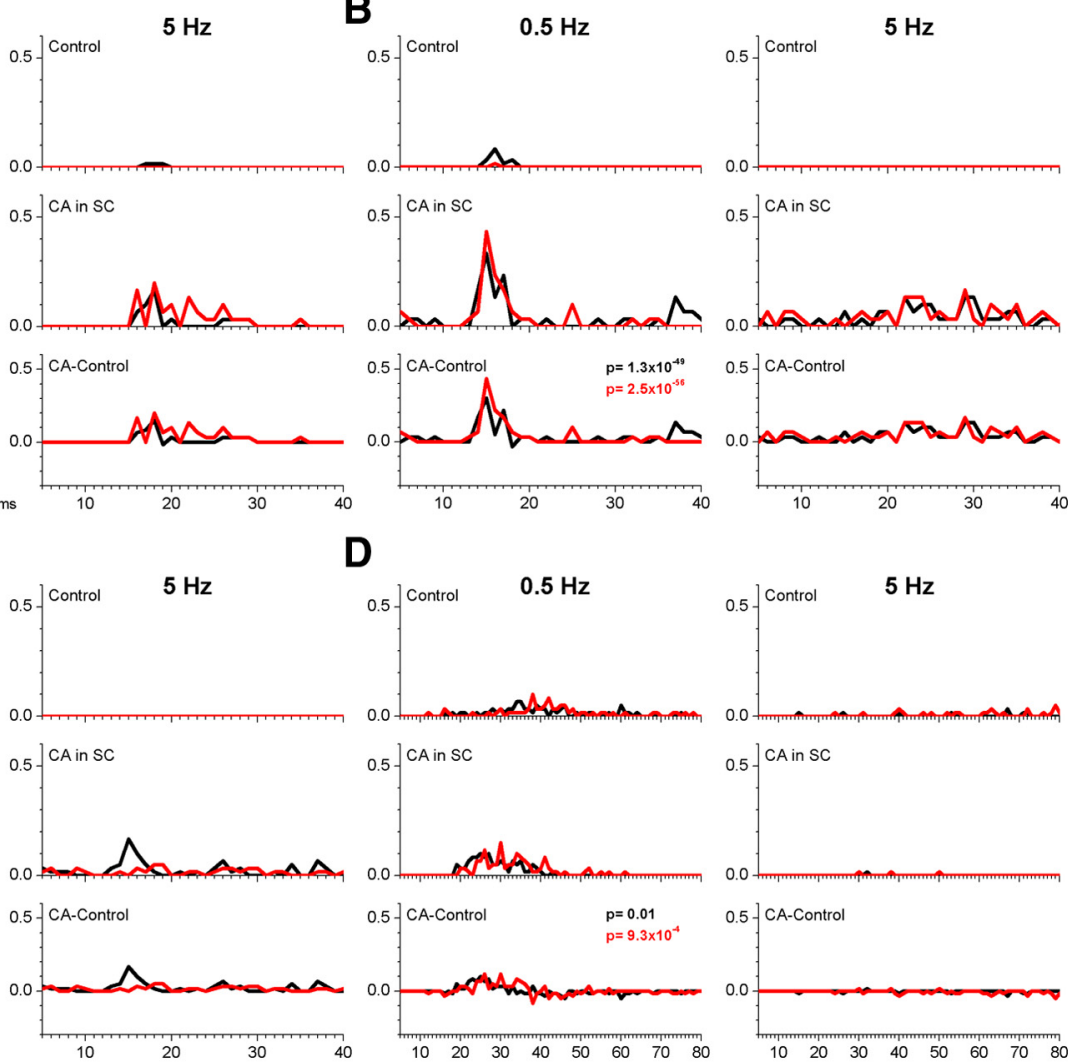

Figure 10. Examples of the effect of $C A$ on single-unit responses evoked by fictive whisking in four different cells $(\boldsymbol{A}-\boldsymbol{D})$. PSTHs are shown before and during application of CA ( $0.5 \mathrm{~mm})$ for two fictive whisking frequencies ( 0.5 and $5 \mathrm{~Hz}$ ). Bottom, The difference ( $C A-C o n t r o l)$ between the drug and the control period responses to denote the changes produced by $C A$. Note that $C A$ typically enhances the evoked responses. The $p$ values of the paired comparison test (Wilcoxon) are displayed.

sion of activity could be determined. None of the cells enhanced their spontaneous firing during application of NE or 5HT. We also tested whether the effect of NE and $5 \mathrm{HT}$ on spontaneous firing could be reproduced by increasing the endogenous levels of monoamines by applying fluoxetine $(1.8 \mathrm{~mm})$, a $5 \mathrm{HT}$ uptake inhibitor that has been shown to increase the extracellular levels of both 5HT and NE (Perry and Fuller, 1997). Similar to 5HT and $\mathrm{NE}$, infusion of fluoxetine $(1.8 \mathrm{mM})$ into the superior colliculus suppressed MUA spontaneous firing (Fig. 9C).

\section{Neuromodulators influence fictive whisking responses in superior colliculus}

Next we tested the effects of CA on fictive whisking responses using single-unit recordings ( $n=11$ cells). Of these cells, four had small responses during fictive whisking and CA had no significant effect on these responses. The other seven cells had significant responses evoked by fictive whisking. Two of those were unaffected by CA, whereas the other five were significantly affected by at least one type (whisking in air or on surfaces at 0.5 or $5 \mathrm{~Hz}$ ) of response (Wilcoxon, control vs CA; $p<0.05$ ). Four of the affected cells are shown in Figure 10. There were two main effects of CA. First, CA makes superior colliculus cells more responsive to low-frequency $(0.5 \mathrm{~Hz})$ whisking movement and active touch (Fig. 10). In some cases, unresponsive cells become responsive during $\mathrm{CA}$. This effect is most obvious in Figure $10 B, C$, which shows the effect of CA on two cells that had small or negligible responses to whisking in air or whisking on a surface during control. During CA, both cells responded robustly to whisking in air and whisking on a surface. Second, CA makes cells respond more robustly to high-frequency $(5 \mathrm{~Hz})$ whisking move- ment and active touch. Consequently, frequency-dependent adaptation is reduced during cholinergic activation in the superior colliculus. This effect of CA adaptation is obvious in the three cells shown in Figures $10 A-C$. During control, these cells had negligible responses during fictive whisking at $5 \mathrm{~Hz}$ but responses emerged during CA.

In contrast to the enhancing effects of CA, both $\mathrm{NE}(n=2$ cells) and 5HT ( $n=4$ cells) suppressed the responses to whisking movement and active touch in all of the six cells tested that had significant responses during control (Fig. 11 shows four of these cells). An additional nine cells were also tested but these had negligible responses during control and neither NE or 5HT unmasked any responses. Thus, although cholinergic activation makes some superior colliculus cells more responsive to whisking movement and active touch, monoaminergic activation suppresses these responses.

\section{Discussion}

Neurons in the intermediate layers of the superior colliculus that are sensitive to passive touch (deflection of stationary whiskers) are also sensitive to whisker movement (fictive whisking in air) and active touch (fictive whisking on a surface). One quarter of these cells discharge selectively during whisker movement, another quarter of these cells discharge selectively during active touch, whereas the remaining cells (two quarters) respond to whisker movement but are also either excited or inhibited by active touch. Whisker movement responses occur selectively during the onset of the whisker protraction between 5 and $20 \mathrm{~ms}$, with either a single peak before $12 \mathrm{~ms}$ (peak1), a single peak after $12 \mathrm{~ms}$ (peak2), or they respond with both of these peaks. The 
A

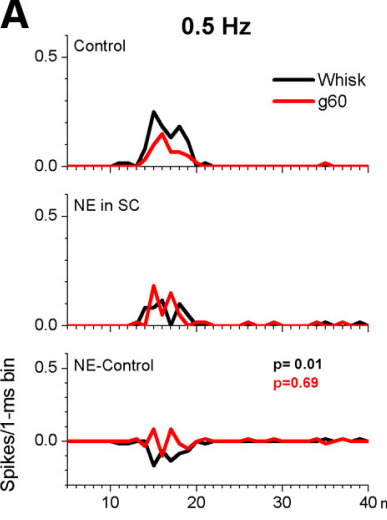

C
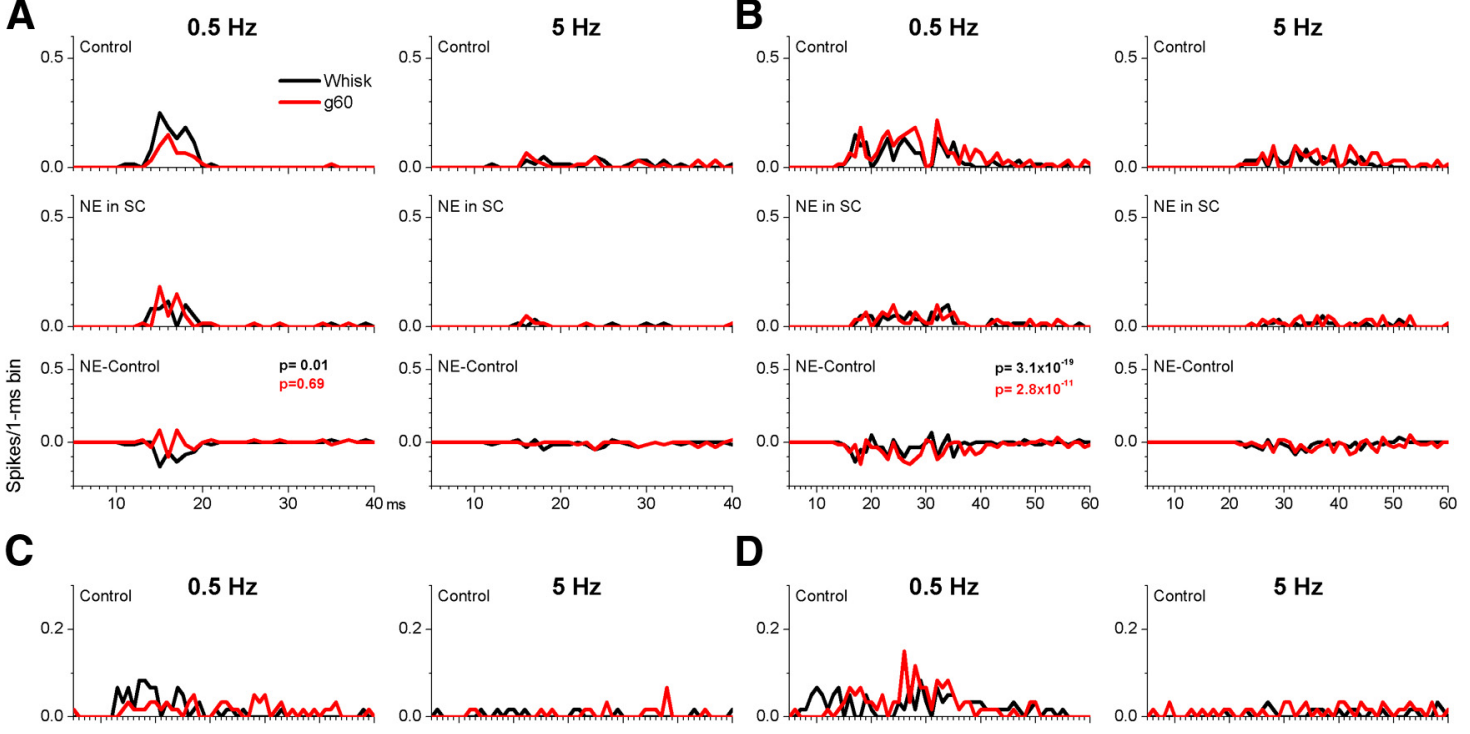

D
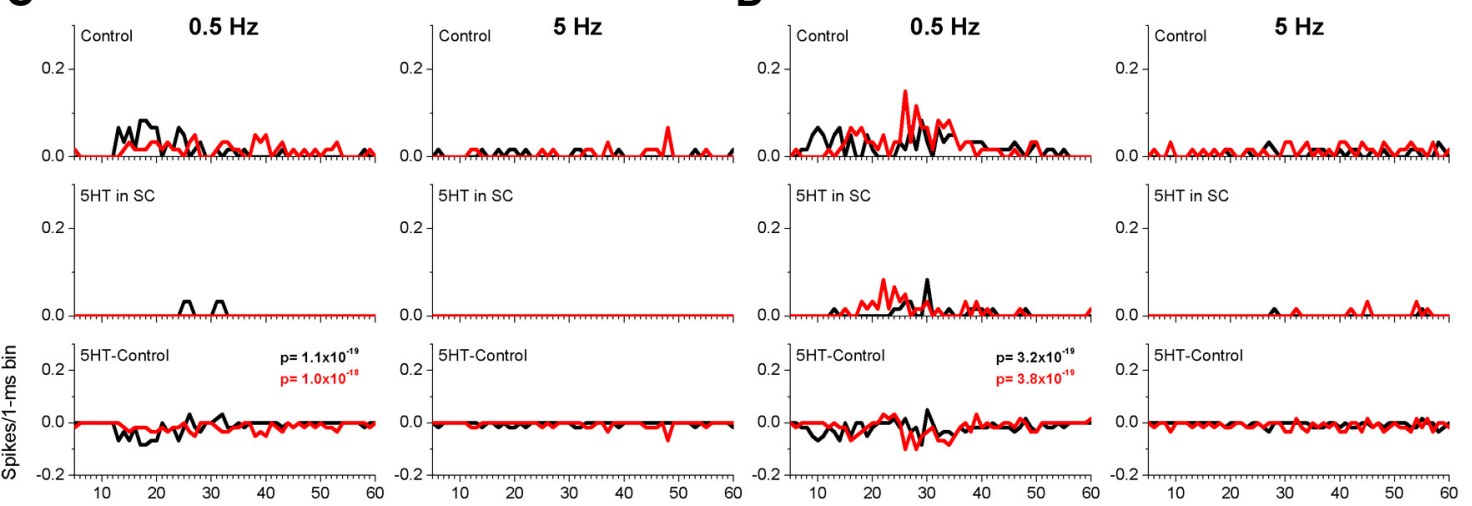

Figure 11. Examples of the effect of NE or $5 \mathrm{HT}$ on single-unit responses evoked by fictive whisking in four different cells $(\boldsymbol{A}-\boldsymbol{D})$ ). PSTHs are shown before and during application of NE ( $0.5 \mathrm{~mm})$ or $5 \mathrm{HT}(0.5 \mathrm{~mm})$ for two fictive whisking frequencies $(0.5$ and $5 \mathrm{~Hz}$ ). Bottom, The difference ( $\mathrm{NE}-$ Control or $5 \mathrm{HT}$ - Control) between the drug and the control period responses to denote the changes produced by the drug. Note that NE and 5HT typically suppress the evoked responses. The $p$ values of the paired comparison test (Wilcoxon) are displayed.

majority of whisker movement cells have a peak2 response, which is mainly driven by corticotectal afferents that feed whisker movement activity from the barrel cortex.

Active touch responses occur later and last longer (15-40 ms) than whisker movement responses, and coincide with the middle portion of the rising phase of the protraction as whiskers brush the surface. A significant portion of the active touch response in superior colliculus is driven by corticotectal activity from barrel cortex. In addition, GABA-mediated synaptic inhibition has powerful control over spontaneous, passive touch, whisker movement, and active touch responses in superior colliculus. Finally, different neuromodulators have selective effects on whisker-sensitive cells in superior colliculus. Cholinergic activation leads to significant increases in spontaneous firing and makes cells more responsive to whisking movement and active touch, particularly at high frequencies. In contrast, noradrenergic or serotoninergic activation (monoaminergic activation) lead to slight but significant decreases in spontaneous firing and responsiveness. Noradrenergic activation appears to differentially affect trigeminotectal and corticotectal inputs by causing suppression and enhancement, respectively.

\section{Cortical control of movement and touch responses in superior colliculus}

Here we determined the role of trigeminotectal and corticotectal excitatory afferents in driving fictive whisking neural activity in superior colliculus. The results indicate that peak1 responses $(<12 \mathrm{~ms})$ driven by whisker movement or active touch are unaffected by manipulating responses in barrel cortex. In contrast, peak 2 responses are highly sensitive to changes in barrel cortex; superior colliculus peak2 responses increased and decreased in unison with barrel cortex responses. Thus, whisker movement and active touch responses in superior colliculus are under the influence of barrel cortex activity. The portion of the whisker movement and active touch response that is influenced by corticotectal activity from barrel cortex occurs between 12 and $40 \mathrm{~ms}$ after whisker movement onset. This period corresponds to the middle segment of the whisker protraction, which crests at $\sim 50$ ms. Thus, whisker movement and active touch activity in superior colliculus is under the direct influence of barrel cortex activity, particularly during the rising phase of the whisker protraction.

\section{Inhibition regulates spontaneous activity and evoked responses}

In addition to the excitatory afferents mentioned above, cells in the intermediate layers of superior colliculus are under inhibitory control from local interneurons and extrinsic sources (Isa and Hall, 2009). The main extrinsic GABAergic input is formed by afferents from the substantia nigra pars reticulata (Di Chiara et al., 1979; Harting et al., 1988; Redgrave et al., 1992; Kaneda et al., 2008). This nigrotectal pathway consists of ipsilateral GABAergic cells that project to the deeper layers of the superior colliculus where they directly contact cells that form the predorsal bundle as well as inhibitory interneurons (Harting et al., 1988; Redgrave et al., 1992; Kaneda et al., 2008). In cats, there is also a smaller contralateral projection, and sensory (visual) inputs have opposing effects on crossed and uncrossed nigrotectal cells (Jiang et al., 2003). The other extrinsic GABAergic input is formed by the incertotectal pathway, which consists of GABAergic cells from 
the zona incerta that project to the superior colliculus (Kim et al., 1992; Kolmac et al., 1998).

We found that block of GABA receptors unmasks robust spontaneous activity, which indicates that the spontaneous activity of whisker-sensitive cells in superior colliculus is under tight inhibitory control. This is significant because many of these cells are characterized by having no spontaneous activity (Hemelt and Keller, 2007; Cohen et al., 2008; Bezdudnaya and CastroAlamancos, 2011). Block of GABA receptors also unmasks passive touch, whisker movement, and active-touch responses in superior colliculus. In fact, without synaptic inhibition, the superior colliculus loses its stereotyped peak 1 and peak2 responses arising from trigeminal and cortical afferents, respectively. Instead, responses last for the duration of the whisker movement sequence. Knowing that whisker evoked responses in superior colliculus are under tight inhibitory control raises important questions for future work, such as what is the contribution of the different sources of inhibition (local, nigrotectal, and incertotectal) to shaping sensory responses and regulating spontaneous activity.

\section{Neuromodulation as a substrate for changes in behavioral state}

Recordings from freely behaving rats has recently revealed that the firing level of whisker-sensitive cells in superior colliculus is controlled by behavioral state (Cohen and Castro-Alamancos, 2010c). The firing rate is high (activated) during active exploration (which includes active whisking) and REM sleep, and much lower (deactivated) during awake immobility and slow-wave sleep (Cohen and Castro-Alamancos, 2010c). Particularly interesting are periods during awake immobility when superior colliculus firing ceases completely. Thus, the superior colliculus appears to come online during active exploratory states and rapidly goes offline during awake immobile periods. In addition, animals are better capable of detecting behaviorally relevant sensory stimuli if superior colliculus cells are in the activated state (Cohen and Castro-Alamancos, 2010b). The observation in the present study that the spontaneous firing of whisker-sensitive cells in the superior colliculus is controlled by synaptic inhibition raises the intriguing possibility that regulation of extrinsic or local inhibitory inputs causes the changes observed in spontaneous firing rate observed during behavior.

Neuromodulators (acting directly or indirectly by regulating inhibition) may also have a role in affecting the spontaneous firing of whisker-sensitive cells in superior colliculus during changes in behavioral states. Several neuromodulatory pathways project to the superior colliculus (see Introduction). Here we found that cholinergic stimulation in the superior colliculus sharply increases the spontaneous firing of whisker-sensitive cells. The activating effects of cholinergic stimulation are in line with the fact that acetylcholine depolarizes some superior colliculus neurons in vitro (Sooksawate and Isa, 2006). Moreover, the enhancing effect of cholinergic stimulation on spontaneous firing is much larger when inhibition is intact, suggesting that it may be partly caused by suppressing inhibition. Indeed, work in vitro has shown that cholinergic stimulation suppresses GABA mediated synaptic currents in superior colliculus (Li et al., 2004). Thus, cholinergic stimulation rapidly activates the superior colliculus and may mediate the enhanced firing observed in behaving animals during active exploration and/or REM sleep.

In contrast to the effect of cholinergic stimulation, we found that monoaminergic stimulation (i.e., noradrenergic or serotoninergic receptors) in the superior colliculus has a suppressive effect on the spontaneous firing of whisker-sensitive cells. A similar contrast between these neuromodulators has been previously found in the whisker thalamus (Hirata et al., 2006; Hirata and Castro-Alamancos, 2010). The suppressive effects of monoaminergic stimulation agree with previous effects of NE applied into the superficial layers of the superior colliculus, which tend to hyperpolarize cells and inhibit spontaneous and visual responses (Kayama and Sato, 1982; Tan et al., 1999). Similarly, 5HT has been shown to suppress visual responses in the superficial layers of the superior colliculus (Mooney et al., 1996). Monoaminergic activation may serve to rapidly suppress superior colliculus firing as dictated by behavioral state.

In addition to the robust changes in firing rates, neuromodulators affected both multi-whisker trigeminotectal (peak1) and corticotectal (peak2) responses differently. Noradrenergic stimulation suppressed trigeminotectal responses but enhanced corticotectal responses. One possibility to explain this finding is that trigeminotectal and corticotectal synapses are differently affected by noradrenergic stimulation. For example, in the whisker thalamus neuromodulators suppress corticothalamic but not trigeminothalamic synapses (Castro-Alamancos and Calcagnotto, 2001; Castro-Alamancos, 2002b). Future work in slices will need to test whether trigeminotectal and corticotectal synapses are differentially affected by noradrenergic receptor activation. In addition, cholinergic stimulation suppressed subthreshold FP responses but not suprathreshold MUA responses. The suppression of subthreshold responses may have been caused by a reduction in EPSP driving force due to the robust depolarization that likely underlies the increased spontaneous firing rate during cholinergic stimulation.

\section{Conclusions}

Our results indicate that whisker-sensitive cells in the intermediate layers of the superior colliculus show whisker movement and touch related activity that is driven by trigeminotectal inputs followed by corticotectal inputs during the rising phase of the whisker protraction. Synaptic inhibition controls spontaneous firing and is necessary for the distinctive peak 1 and peak 2 responses evoked by whisker stimulation to occur. Cholinergic and monoaminergic neuromodulation differently regulate evoked responses as well as the spontaneous firing of superior colliculus cells, and may set the distinct neural activity levels observed during different behavioral states.

\section{References}

Aguilar JR, Castro-Alamancos MA (2005) Spatiotemporal gating of sensory inputs in thalamus during quiescent and activated states. J Neurosci 25: 10990-11002. CrossRef Medline

Beitz AJ, Clements JR, Mullett MA, Ecklund LJ (1986) Differential origin of brainstem serotoninergic projections to the midbrain periaqueductal gray and superior colliculus of the rat. J Comp Neurol 250:498-509. CrossRef Medline

Beninato M, Spencer RF (1986) A cholinergic projection to the rat superior colliculus demonstrated by retrograde transport of horseradish peroxidase and choline acetyltransferase immunohistochemistry. J Comp Neurol 253:525-538. CrossRef Medline

Bezdudnaya T, Castro-Alamancos MA (2011) Superior colliculus cells sensitive to active touch and texture during whisking. J Neurophysiol 106: 332-346. CrossRef Medline

Billet S, Cant NB, Hall WC (1999) Cholinergic projections to the visual thalamus and superior colliculus. Brain Res 847:121-123. CrossRef Medline

Brown AW, Waite PM (1974) Responses in the rat thalamus to whisker movements produced by motor nerve stimulation. J Physiol 238:387401. Medline

Carvell GE, Simons DJ (1990) Biometric analyses of vibrissal tactile discrimination in the rat. J Neurosci 10:2638-2648. Medline 
Castro-Alamancos MA (1999) Neocortical synchronized oscillations induced by thalamic disinhibition in vivo. J Neurosci 19:RC27. Medline

Castro-Alamancos MA (2000) Origin of synchronized oscillations induced by neocortical disinhibition in vivo. J Neurosci 20:9195-9206. Medline

Castro-Alamancos MA (2002a) Different temporal processing of sensory inputs in the rat thalamus during quiescent and information processing states in vivo. J Physiol 539:567-578. CrossRef Medline

Castro-Alamancos MA (2002b) Properties of primary sensory (lemniscal) synapses in the ventrobasal thalamus and the relay of high-frequency sensory inputs. J Neurophysiol 87:946-953. Medline

Castro-Alamancos MA (2004) Dynamics of sensory thalamocortical synaptic networks during information processing states. Prog Neurobiol 74: 213-247. CrossRef Medline

Castro-Alamancos MA, Borrell J (1993) Motor activity induced by disinhibition of the primary motor cortex of the rat is blocked by a non-NMDA glutamate receptor antagonist. Neurosci Lett 150:183-186. CrossRef Medline

Castro-Alamancos MA, Borrell J (1995) Contribution of NMDA and nonNMDA glutamate receptors to synchronized excitation and cortical output in the primary motor cortex of the rat. Brain Res Bull 37:539-543. CrossRef Medline

Castro-Alamancos MA, Calcagnotto ME (2001) High-pass filtering of corticothalamic activity by neuromodulators released in the thalamus during arousal: in vitro and in vivo. J Neurophysiol 85:1489-1497. Medline

Castro-Alamancos MA, Oldford E (2002) Cortical sensory suppression during arousal is due to the activity-dependent depression of thalamocortical synapses. J Physiol 541:319-331. CrossRef Medline

Cohen JD, Castro-Alamancos MA (2007) Early sensory pathways for detection of fearful conditioned stimuli: tectal and thalamic relays. J Neurosci 27:7762-7776. CrossRef Medline

Cohen JD, Castro-Alamancos MA (2010a) Detection of low salience whisker stimuli requires synergy of tectal and thalamic sensory relays. J Neurosci 30:2245-2256. CrossRef Medline

Cohen JD, Castro-Alamancos MA (2010b) Neural correlates of active avoidance behavior in superior colliculus. J Neurosci 30:8502-8511. CrossRef Medline

Cohen JD, Castro-Alamancos MA (2010c) Behavioral state dependency of neural activity and sensory (whisker) responses in superior colliculus. J Neurophysiol 104:1661-1672. CrossRef Medline

Cohen JD, Hirata A, Castro-Alamancos MA (2008) Vibrissa sensation in superior colliculus: wide-field sensitivity and state-dependent cortical feedback. J Neurosci 28:11205-11220. CrossRef Medline

Di Chiara G, Porceddu ML, Morelli M, Mulas ML, Gessa GL (1979) Evidence for a GABAergic projection from the substantia nigra to the ventromedial thalamus and to the superior colliculus of the rat. Brain Res 176:273-284. CrossRef Medline

Gandhi NJ, Katnani HA (2011) Motor functions of the superior colliculus. Annu Rev Neurosci 34:205-231. CrossRef Medline

Gao P, Bermejo R, Zeigler HP (2001) Whisker deafferentation and rodent whisking patterns: behavioral evidence for a central pattern generator. J Neurosci 21:5374-5380. Medline

Grunwerg BS, Krauthamer GM (1990) Vibrissa-responsive neurons of the superior colliculus that project to the intralaminar thalamus of the rat. Neurosci Lett 111:23-27. CrossRef Medline

Harting JK, Huerta MF, Hashikawa T, Weber JT, Van Lieshout DP (1988) Neuroanatomical studies of the nigrotectal projection in the cat. J Comp Neurol 278:615-631. CrossRef Medline

Hemelt ME, Keller A (2007) Superior sensation: superior colliculus participation in rat vibrissa system. BMC Neurosci 8:12. CrossRef Medline

Hemelt ME, Keller A (2008) Superior colliculus control of vibrissa movements. J Neurophysiol 100:1245-1254. CrossRef Medline

Hirata A, Castro-Alamancos MA (2010) Neocortex network activation and deactivation states controlled by the thalamus. J Neurophysiol 103:11471157. CrossRef Medline

Hirata A, Aguilar J, Castro-Alamancos MA (2006) Noradrenergic activation amplifies bottom-up and top-down signal-to-noise ratios in sensory thalamus. J Neurosci 26:4426-4436. CrossRef Medline

Hirata A, Aguilar J, Castro-Alamancos MA (2009) Influence of subcortical inhibition on barrel cortex receptive fields. J Neurophysiol 102:437-450. CrossRef Medline

Isa T, Hall WC (2009) Exploring the superior colliculus in vitro. J Neurophysiol 102:2581-2593. CrossRef Medline

Jiang H, Stein BE, McHaffie JG (2003) Opposing basal ganglia processes shape midbrain visuomotor activity bilaterally. Nature 423:982-986. CrossRef Medline

Kaneda K, Isa K, Yanagawa Y, Isa T (2008) Nigral inhibition of GABAergic neurons in mouse superior colliculus. J Neurosci 28:11071-11078. CrossRef Medline

Kayama Y, Sato H (1982) Effects of locus coeruleus stimulation on neuronal activities in the rat superior colliculus. Jpn J Physiol 32:1011-1014. CrossRef Medline

Khatri V, Bermejo R, Brumberg JC, Keller A, Zeigler HP (2009) Whisking in air: encoding of kinematics by trigeminal ganglion neurons in awake rats. J Neurophysiol 101:1836-1846. CrossRef Medline

Kim U, Gregory E, Hall WC (1992) Pathway from the zona incerta to the superior colliculus in the rat. J Comp Neurol 321:555-575. CrossRef Medline

Kleinfeld D, Deschênes M (2011) Neuronal basis for object location in the vibrissa scanning sensorimotor system. Neuron 72:455-468. CrossRef Medline

Kleinfeld D, Ahissar E, Diamond ME (2006) Active sensation: insights from the rodent vibrissa sensorimotor system. Curr Opin Neurobiol 16:435444. CrossRef Medline

Kolmac CI, Power BD, Mitrofanis J (1998) Patterns of connections between zona incerta and brainstem in rats. J Comp Neurol 396:544-555. CrossRef Medline

Krauthamer GM, Grunwerg BS, Krein H (1995) Putative cholinergic neurons of the pedunculopontine tegmental nucleus projecting to the superior colliculus consist of sensory responsive and unresponsive populations which are functionally distinct from other mesopontine neurons. Neuroscience 69:507-517. CrossRef Medline

Krauzlis RJ, Lovejoy LP, Zénon A (2013) Superior colliculus and visual spatial attention. Annu Rev Neurosci 36:165-182. CrossRef Medline

Li F, Endo T, Isa T (2004) Presynaptic muscarinic acetylcholine receptors suppress GABAergic synaptic transmission in the intermediate grey layer of mouse superior colliculus. Eur J Neurosci 20:2079-2088. CrossRef Medline

McHaffie JG, Stein BE (1982) Eye movements evoked by electrical stimulation in the superior colliculus of rats and hamsters. Brain Res 247:243253. CrossRef Medline

McHaffie JG, Kao CQ, Stein BE (1989) Nociceptive neurons in rat superior colliculus: response properties, topography, and functional implications. J Neurophysiol 62:510-525. Medline

Mooney RD, Huang X, Shi MY, Bennett-Clarke CA, Rhoades RW (1996) Serotonin modulates retinotectal and corticotectal convergence in the superior colliculus. Prog Brain Res 112:57-69. CrossRef Medline

Oldford E, Castro-Alamancos MA (2003) Input-specific effects of acetylcholine on sensory and intracortical evoked responses in the "barrel cortex" in vivo. Neuroscience 117:769-778. CrossRef Medline

Perry KW, Fuller RW (1997) Fluoxetine increases norepinephrine release in rat hypothalamus as measured by tissue levels of MHPG-SO4 and microdialysis in conscious rats. J Neural Transm 104:953-966. CrossRef Medline

Redgrave P, Marrow L, Dean P (1992) Topographical organization of the nigrotectal projection in rat: evidence for segregated channels. Neuroscience 50:571-595. CrossRef Medline

Sommer MA, Wurtz RH (2008) Brain circuits for the internal monitoring of movements. Annu Rev Neurosci 31:317-338. CrossRef Medline

Sooksawate T, Isa T (2006) Properties of cholinergic responses in neurons in the intermediate grey layer of rat superior colliculus. Eur J Neurosci 24:3096-3108. CrossRef Medline

Sparks DL, Mays LE (1990) Signal transformations required for the generation of saccadic eye movements. Annu Rev Neurosci 13:309-336. CrossRef Medline

Steinbusch HW (1981) Distribution of serotonin-immunoreactivity in the central nervous system of the rat-cell bodies and terminals. Neuroscience 6:557-618. CrossRef Medline

Swanson LW, Hartman BK (1975) The central adrenergic system: an immunofluorescence study of the location of cell bodies and their efferent connections in the rat utilizing dopamine-beta-hydroxylase as a marker. J Comp Neurol 163:467-505. CrossRef Medline

Szwed M, Bagdasarian K, Ahissar E (2003) Encoding of vibrissal active touch. Neuron 40:621-630. CrossRef Medline

Tan H, Mooney RD, Rhoades RW (1999) Effects of norepinephrine upon superficial layer neurons in the superior colliculus of the hamster: in vitro studies. Vis Neurosci 16:557-570. Medline

Zucker E, Welker WI (1969) Coding of somatic sensory input by vibrissae neurons in the rat's trigeminal ganglion. Brain Res 12:138-156. CrossRef Medline 